Research Article

\title{
Influence of Reinforcement Length on Singularity of Single-Lap Joints
}

\author{
Yuqi Wang, ${ }^{1}$ Yanhui Li $\mathbb{D}^{1,2}$ and Kaixuan Zhou' \\ ${ }^{1}$ Faculty of Mechanical and Electrical Engineering, Qingdao University, Qingdao 266071, China \\ ${ }^{2}$ Laboratory of Fiber Materials and Modern Textile, The Growing Base for State Key Laboratory, Qingdao University, \\ Qingdao 266071, China
}

Correspondence should be addressed to Yanhui Li; liyanhui@tsinghua.org.cn

Received 20 March 2018; Revised 13 June 2018; Accepted 24 June 2018; Published 18 July 2018

Academic Editor: Michele Zappalorto

Copyright (c) 2018 Yuqi Wang et al. This is an open access article distributed under the Creative Commons Attribution License, which permits unrestricted use, distribution, and reproduction in any medium, provided the original work is properly cited.

\begin{abstract}
In order to enhance the strength of single-lap joints, the single-lap joints with reinforcements were proposed. The influence of reinforcement length on the singular behavior near to the interface point of single-lap joints was investigated theoretically and numerically. The theoretical strength of singularity point was calculated by Bogy determinant. Stresses along the interface close to the singularity points were calculated with finite element analyses (FEAs). Results showed that the singular stress intensity factor of single-lap joints can be decreased by the reinforcement. However, the singular stress intensity factor of single-lap joints with reinforcements was decreased slightly with increasing reinforcement length.
\end{abstract}

\section{Introduction}

Recently, adhesive bonding is widely used in light-weight design such as aerospace industry and automobile industry [1]. Adhesive bonding is one of these new methods that are becoming common, especially in situations where the joints are between materials that are dissimilar, difficult to weld, or have been precoated [2-4]. However, the debonding easily happens at the interface point of the adhesive bonding because of the singular behavior, and it is useful for assessing the strength of adhesive bonding through analyzing singular behavior.

The failure loads of adhesive joints with the variation of bondline thickness were predicted by the critical stress intensity in Van Tooren et al.'s stress singularity model [5]. They found good correlation between the failure loads versus bondline thickness and the experimental results.

In Breto et al.'s study [6], two independent methodologies were proposed for selecting the intermediate material between adhesive bands in mixed adhesive joints attending to the singularity impact. The first one is based on an analytical approach for calculating the root locus varying Young's modulus, and the second one is based on the influence of distance (instead of the order) on the singular term. The same result obtained from two different methodologies was summarized, and the feasibility of different methodologies was also discussed.

The influence of bondline thickness on the static strength and fatigue life of single-lap joints was reported in Tang et al.'s paper [7] using generalized stress singularity approach. The test results were analyzed and compared to the simulation results. Results showed that the static strength decreased with increasing bondline thickness. The failure initiated at the interface of thick composite laminate singlelap joints with the thick bondline. The generalized stress singularity approach provided a viable method for predicting the failure initiation of thick composite laminate single-lap joints.

The effect of different material and geometric parameters (the ratio of the adherend lengths, the ratio of the adherend thickness, and Young's modulus ratio between different adherends) on stress state near the interface point of the 
single-lap joints using the finite element analysis (FEA) and experimental measurements were studied in Sawa et al.'s paper [8]. It was observed that the singular behavior occurs near the interface point, and the stress increased with decreasing Young's modulus of adherend and increased with decreasing thickness.

The effect of various geometric parameters (adhesive thickness, bond length, and angle and shape of the adhesive edge) on the singular behavior of single-lap joints for a total of 30 cases was reported in Goglio et al.'s paper [9]. Results showed that the less influencing parameter is the edge shape (straight edge and fillet edge) and the most influencing parameter is edge angle. The singular stress field increases or reduces uniformly with increasing bond length and amplifies evidently with the bondline increasing in case of square edge.

Zhang et al. [10] investigated the variation of stress intensity factors with different material combinations. Dundurs' parameters ( $\alpha$ and $\beta$ ) were used for calculating the stress intensity factors with different cracks (central internal interface cracks, periodic interface cracks, and edge interface cracks) by the FEA. When Dundurs' parameters $\alpha$ and $\beta$ were defined value 0.2 and 0.3 , respectively, the stress intensity factors reached maximum value. When Dundurs' parameters $\alpha$ and $\beta$ were defined value 1 and 0 , respectively, the stress intensity factors reached minimum value.

Noda et al. [11] explored the debonding strength of adhesive joints with and without fictitious crack using the singular stress intensity at the interface point. The critical stress intensity at the interface point can be used to evaluate the strength of adhesive joints. This approach provided a convenient method for predicting the debonding strength of adhesive joints with and without fictitious crack.

The influence of bondline thickness on singular behavior of single-lap joints was discussed in Gleich et al.'s study [12]. In order to enhance the singularity accurately, considerable mesh refinement was necessary in the region around the singularity point. The size of the smallest element was only $0.00005 \mathrm{~mm}$ around the singularity point. They found that the linear region identifies the singularity field appeared in $0.00001 \mathrm{~mm}<r<0.001 \mathrm{~mm}$. The stress intensity factor of the singularity point reached maximum value when the bondline thickness was defined $0.02 \mathrm{~mm}$.

Zhou et al. [13] explored the influence of singular behavior on the stress distribution at the crack tip of rectangular bond specimen by three-dimensional finite element models. The influence of singular behavior increased with the decreasing distance from the interface point.

Kilic et al. [14] discussed the influence of the adhesive overflow on the singular stress state of single-lap joints by a global-local finite element technique. This method has obvious advantages in description of the stress state in the critical regions of single-lap joints without a fine mesh. The results showed that the adhesive overflow can improve the adhesive strength. The energy release rate and the strain energy density criterion may be beneficial in identifying adhesive strength and failure sites.

In many cases, the singularity parameters (stress intensity factor and singularity order) cannot be calculated strictly. The apparent singularity parameters were used for calculating the endurance limits of adhesive joints including and excluding the crack in Imanaka et al.'s study [15]. The fatigue strength of adhesive joints decreased with decreasing lap length. However, the fatigue strength of adhesive joints excluding the crack decreased sharply.

There are many articles focusing the influence of various geometric parameters on singular behavior at the interface point of single-lap joints. In the authors' previous study [16], the effects of stiffness at the end of the overlap on the strength of single-lap joints were studied and reinforcement of the single-lap joint was proposed. The effects of reinforcements with different lengths on the singularity at the interface point of single-lap joints were investigated through Bogy determinant and FEA in this paper.

\section{Determination of the Singularity Parameters around the Singularity Point}

Bogy and Wang $[17,18]$ derived characteristic equations to determine the singularity order $\lambda$. The strength of the singularity points of single-lap joint can be obtained by the characteristic equations.

For the wedge of Figure 1(b), the transcendental equation that determines the singularity strength taken from Bogy is as follows:

$$
D\left(\gamma_{1}, \gamma_{2}, \alpha, \beta ; p\right)=a \beta^{2}+2 b \alpha \beta+2 d \beta+2 e \alpha+f,
$$

where $p$ is the characteristic value that satisfies the condition $D=0, \gamma_{1}$ and $\gamma_{2}$ are the angles of the free edges of the two materials, and $\alpha$ and $\beta$ are the Dundurs constants.

$$
\begin{aligned}
& a\left(\gamma_{1}, \gamma_{2} ; p\right)=4 \phi\left(p, \gamma_{1}\right) 4 \phi\left(p, \gamma_{2}\right), \\
& b\left(\gamma_{1}, \gamma_{2} ; p\right)=2 p^{2} \sin ^{2}\left(\gamma_{1}\right) \phi\left(p, \gamma_{2}\right)+2 p^{2} \sin ^{2}\left(\gamma_{2}\right) \phi\left(p, \gamma_{1}\right), \\
& c\left(\gamma_{1}, \gamma_{2} ; p\right)=4 p^{2}\left(p^{2}-1\right) \sin ^{2}\left(\gamma_{1}\right) \sin ^{2}\left(\gamma_{2}\right)+\phi\left(p, \gamma_{1}-\gamma_{2}\right), \\
& d\left(\gamma_{1}, \gamma_{2} ; p\right)=2 p^{2}\left[\sin ^{2}\left(\gamma_{2}\right) \sin ^{2}\left(p \gamma_{1}\right)-\sin ^{2}\left(\gamma_{1}\right) \sin ^{2}\left(p \gamma_{2}\right)\right], \\
& e\left(\gamma_{1}, \gamma_{2} ; p\right)=-d\left(\gamma_{1}, \gamma_{2} ; p\right)+\phi\left(p, \gamma_{1}\right)-\phi\left(p, \gamma_{2}\right), \\
& f\left(\gamma_{1}, \gamma_{2} ; p\right)=\phi\left[p,\left(\gamma_{1}+\gamma_{2}\right)\right],
\end{aligned}
$$

in which the auxiliary function $\phi(p, x)$ is defined by

$$
\phi(p, x)=\sin ^{2}(p x)-p^{2} \sin ^{2}(x),
$$

where $x$ is in radians.

$$
\begin{aligned}
\alpha & =\frac{G_{1} m_{2}-G_{2} m_{1}}{G_{1} m_{2}+G_{2} m_{1}}, \\
\beta & =\frac{G_{1}\left(m_{2}-2\right)-G_{2}\left(m_{1}-2\right)}{G_{1} m_{2}+G_{2} m_{1}} . \\
G_{i} & =\frac{E_{i}}{2\left(1+v_{i}\right)}, \quad i=1,2 .
\end{aligned}
$$

For plane strain,

$$
m_{i}=4\left(1-v_{i}\right), \quad i=1,2 .
$$




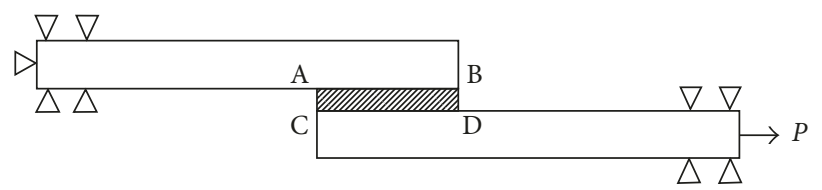

(a)

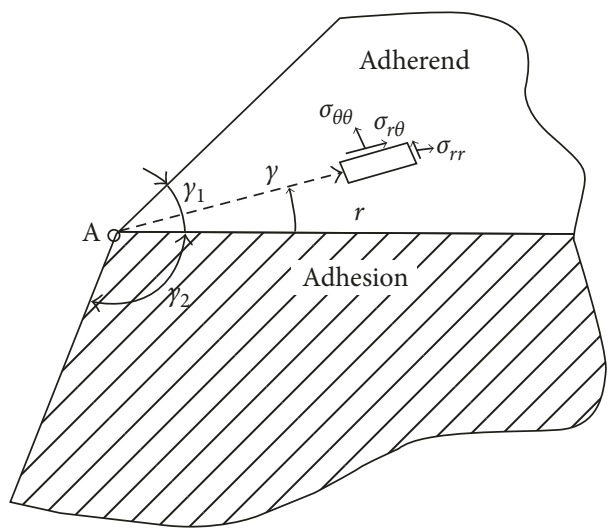

(b)

FIGURE 1: Model of bimaterial interface point. (a) Geometry of single-lap joints; (b) model of bimaterial interface.

TABLE 1: Material parameters and single-lap geometry.

Adherend Young's modulus (MPa)

Adhesive Young's modulus ( $\mathrm{MPa})$

69450

Adherend Poisson ratio

Adhesive Poisson ratio

0.33

Adherend thickness, $t(\mathrm{~mm})$

0.35

Adhesive thickness, $d(\mathrm{~mm})$

2

Overlap length, $L(\mathrm{~mm})$

0.2

Free adherend length, $l(\mathrm{~mm})$

20

Applied load, $P(\mathrm{MPa})$

Reinforcement thickness, $h(\mathrm{~mm})$

90

Reinforcement length, $R$ ( $\mathrm{mm})$

$\Delta R=R-L, \Delta R(\mathrm{~mm})$

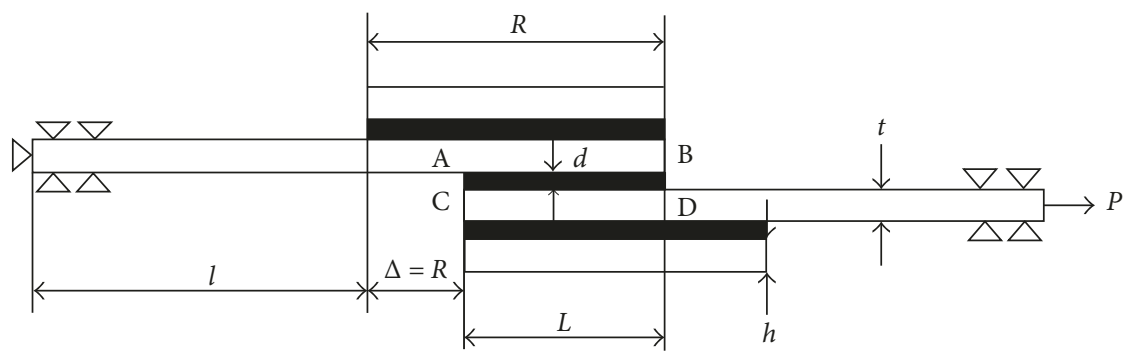

Figure 2: Boundary conditions.

For plane stress,

$$
m_{i}=\frac{4}{\left(1+v_{i}\right)}, \quad i=1,2 .
$$

The singularity order is defined by $\lambda=1-p$, and $\lambda$ depends only on the corner geometry (defined by $\gamma_{1}$ and $\gamma_{2}$ ) and elastic constants of the materials around the singularity. The range of values lies within $0<\lambda<1$. $\lambda$ is not generally equal to
0.5 as it is for a sharp crack in isotropic materials. Effectively, $\lambda$ describes the shape of the stress field around the singularity and $H$ describes the magnitude of the stress field.

The solution for the generic stress component $\sigma_{i j}$ (with $i j=r, \theta)$ is written in the following form [11]:

$$
\sigma_{i j}=\sum_{k=0}^{N} H_{k} r^{-\lambda_{k}} \cdot f_{i j k}(\lambda, \theta)+\sigma_{i j}(\theta),
$$




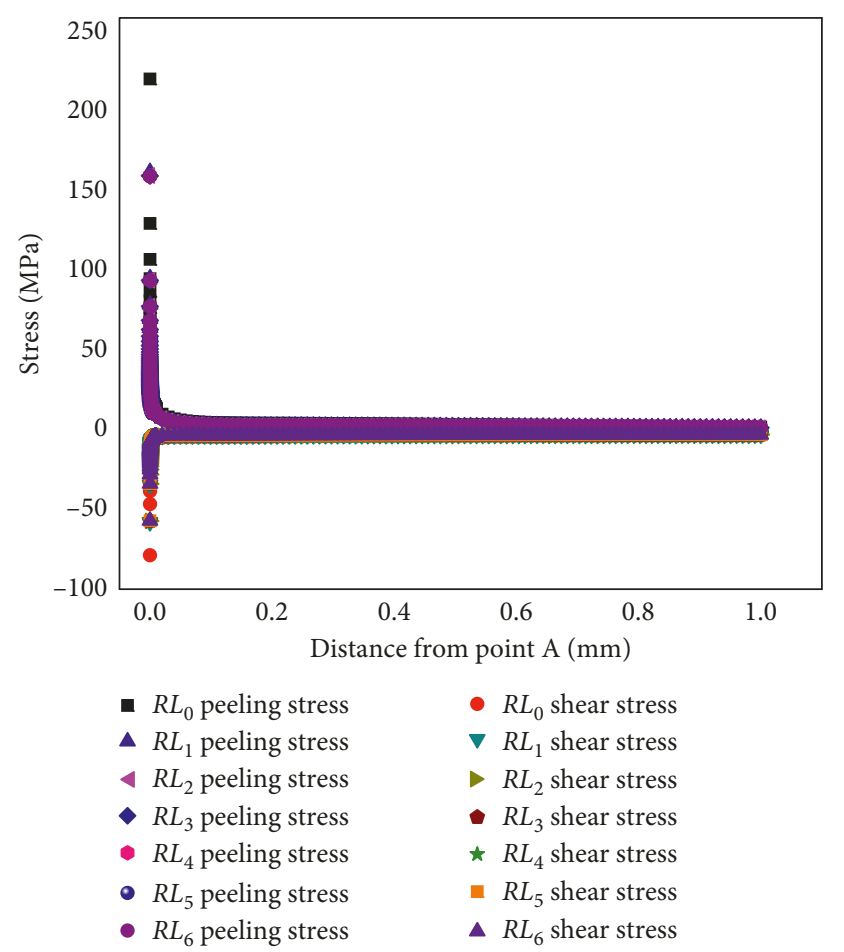

Figure 3: Stress distributions near the singularity point A.

where $H_{k}$ is the SIF corresponding to the $k$ th root, $f_{i j k}(\lambda, \theta)$ is the angular function, and $\sigma_{i j}(\theta)$ are thermal stresses. More typically, this equation is simplified to one term with thermal stresses ignored:

$$
\sigma_{i j}=\sum_{k=0}^{N} H_{k} r^{-\lambda_{k}} \cdot f_{i j k}(\lambda, \theta) .
$$

For the peel stresses and the shear stresses, (8) can be written as

$$
\begin{aligned}
& \sigma_{\theta \theta}\left(r, \theta_{0}\right)=H r^{-\lambda} f_{\theta \theta}\left(\theta_{0}\right), \quad \text { where } H_{\sigma}=H f_{\theta \theta}, \\
& \tau_{r \theta}\left(r, \theta_{0}\right)=H r^{-\lambda} f_{r \theta}\left(\theta_{0}\right), \quad \text { where } H_{\tau}=H f_{r \theta} .
\end{aligned}
$$

By using the peel and shear stresses date around the singularity, such as that obtained by finite element analysis, two expressions can be derived to determine both $\lambda$ and $H$. Taking $\lg$ of (9) and (10) yields the following equations:

$$
\begin{aligned}
& \lg \sigma_{\theta \theta}=-\lambda \lg r+\lg H_{\sigma}, \\
& \lg \tau_{r \theta}=-\lambda \lg r+\lg H_{\tau} .
\end{aligned}
$$

Equation (11) implies that a plot of $\lg \sigma_{F E}$ ( $y$-axis) versus $\lg (r)$ ( $x$-axis) will yield a linear graph with slope $\lambda$. The stress intensity, $H_{\sigma}$, can be calculated from the intercept on the $y$-axis. The same can be done for $H_{\tau}$ using (12).

\section{Finite Element Analysis and Results}

A linear 2D FEA was performed on a single-lap joint by the software ANSYS (ANSYS Inc, Pittsburgh, United States)

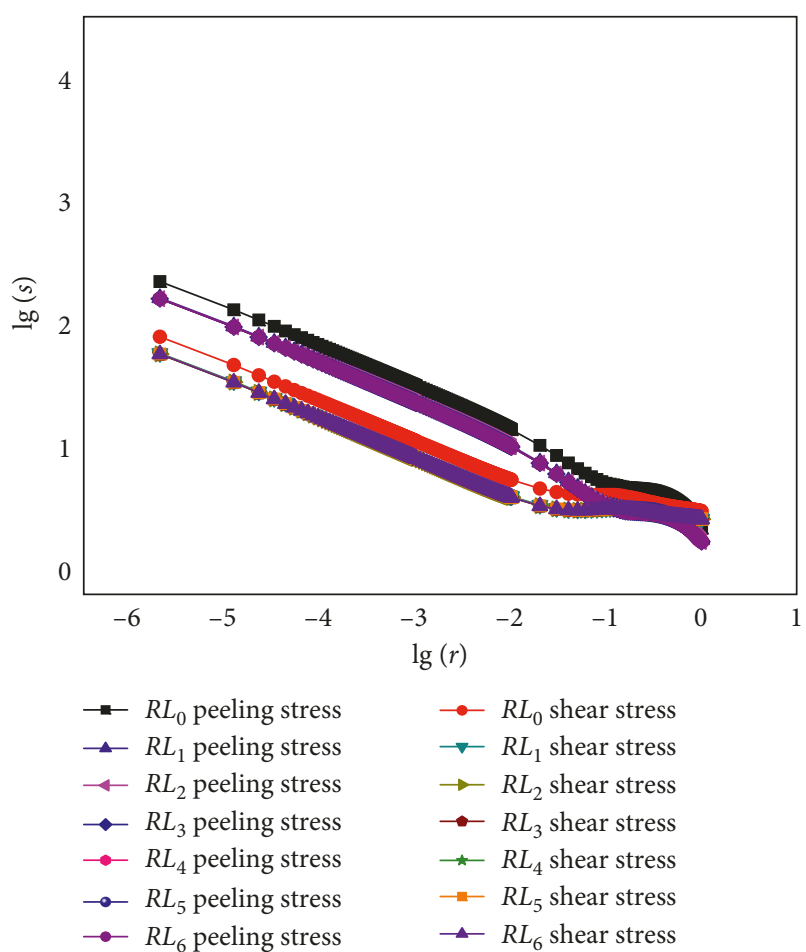

FIGURE 4: $\lg (s)-\lg (r)$.

with material parameters defined in Table 1 . The substrates and reinforcements are defined as aluminium alloy. The adhesive is defined as structural acrylate adhesive [16]. Boundary conditions and configuration are illustrated in Figure 2. The numerical models were adopted with 4-node plane strain elements with $20 \mathrm{MPa}$ stress. Although two singularities exist at each end of the overlap points $\mathrm{A}, \mathrm{B}, \mathrm{C}$, and $\mathrm{D}$ of lap joints, only the strongest singularity, which is of most interest, was investigated [5]. Although the reinforcement adds new corner points, the points A and D are still the strongest singularity points. The failure initiated at the strongest singularity points [7]. Points A and D are both the strongest singularity points and the symmetry points. So point A was selected for singularity analysis. To enhance the singularity accurately, considerable mesh refinement was necessary in the region around the point A. The size of the smallest element was only $1.0 \times 10^{-6} \mathrm{~mm}$. The following nomenclature was used in this study: $R L_{0}$ joints (single-lap joints without reinforcements), $R L_{1}$ joints $(R=30 \mathrm{~mm}), R L_{2}$ joints $(R=40 \mathrm{~mm}), R L_{3}$ joints $(R=50 \mathrm{~mm}), R L_{4}$ joints $(R=60 \mathrm{~mm}), \quad R L_{5}$ joints $(R=70 \mathrm{~mm})$, and $R L_{6}$ joints $(R=80 \mathrm{~mm})$.

Stresses along the interface (line AB in Figure 2) close to the singularity point A were investigated for the range of reinforcement length given in Table 1. In this way, a stress field equation can be derived based on the FEA results for each reinforcement length. Figures 3 and 4 plot the peel and shear stresses date, $s$-stress, and $r$-distance, respectively, close to the point $\mathrm{A}$ along the interface $\mathrm{AB}$. It can be seen that there is a linear region in the range $5<\lg (r)<3$ or $0.00001 \mathrm{~mm}<r<0.001 \mathrm{~mm}$ and nonlinear region where 


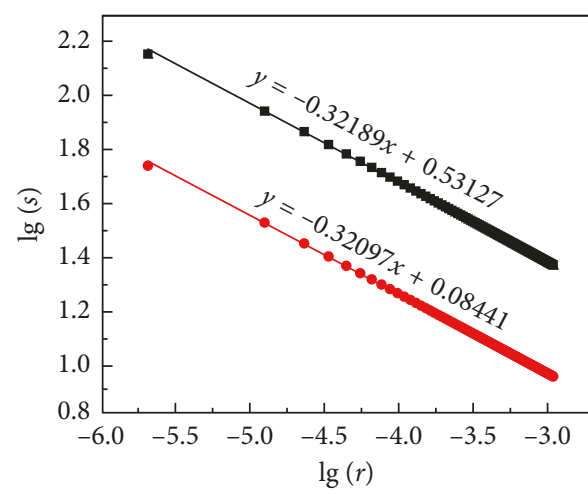

- Peeling stress

- Shear stress

(a)

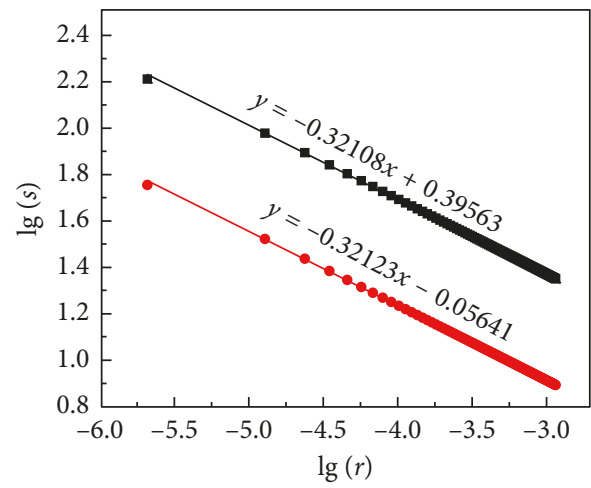

- Peeling stress

- Shear stress

(c)

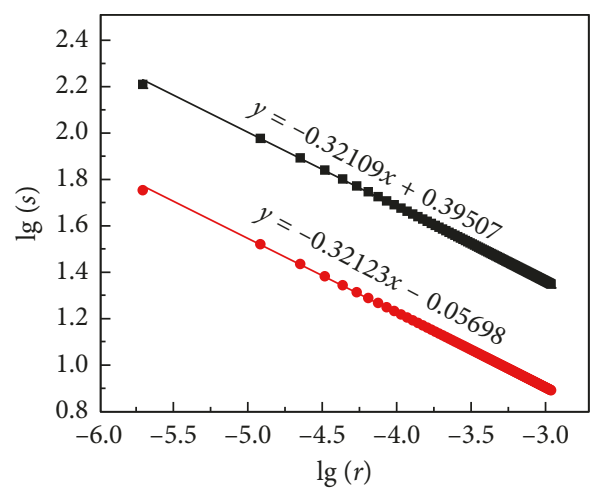

- Peeling stress

- Shear stress

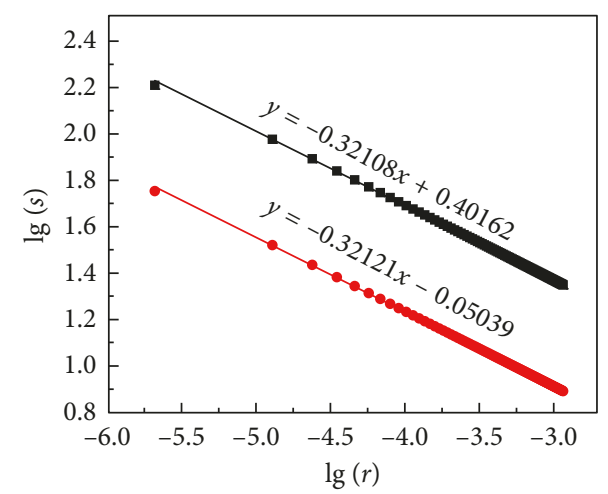

- Peeling stress

- Shear stress

(b)

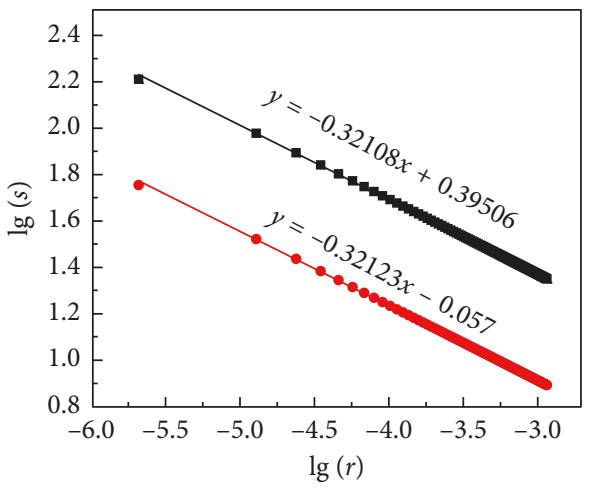

- Peeling stress

- Shear stress

(d)

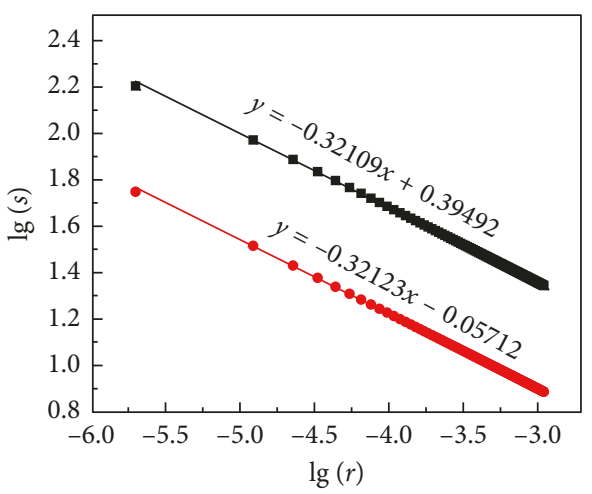

- Peeling stress

- Shear stress

(e)

Figure 5: Continued. 


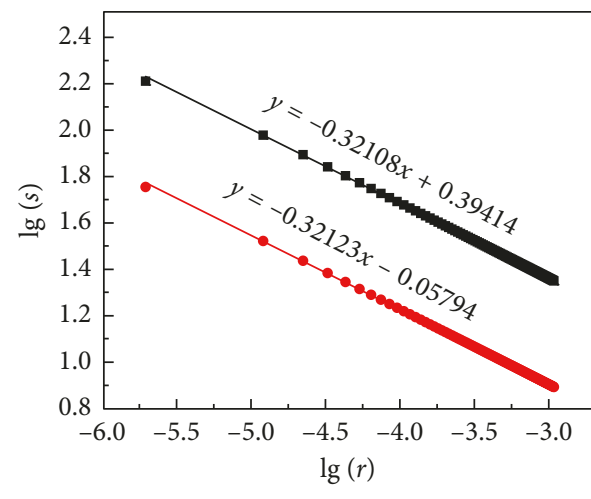

- Peeling stress

- Shear stress

(g)

Figure 5: Fitting straight line and results. (a) $R L_{0}$ joints, (b) $R L_{1}$ joints, (c) $R L_{2}$ joints, (d) $R L_{3}$ joints, (e) $R L_{4}$ joints, (f) $R L_{5}$ joints, and (g) $R L_{6}$ joints.

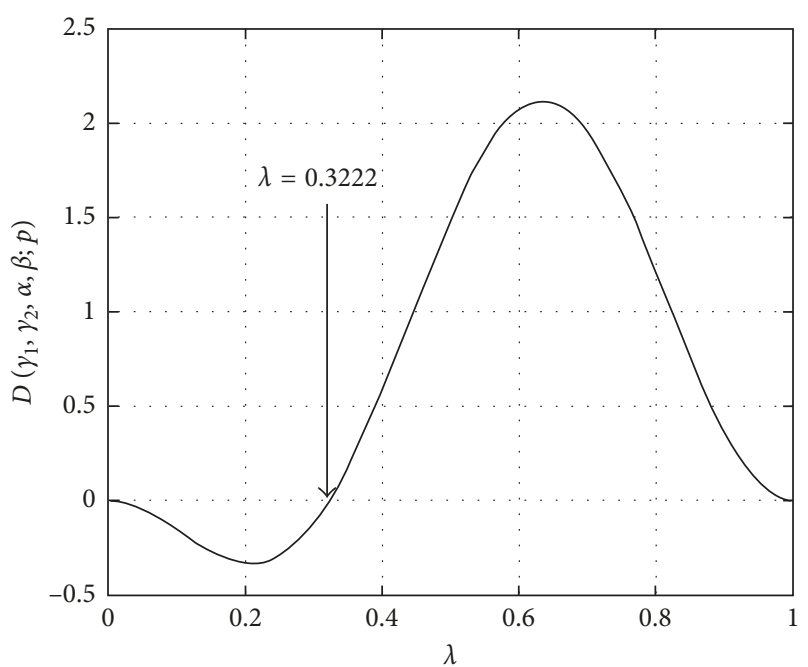

FIGURE 6: Calculated results of the characteristic equation.

$\lg (r)>-3$. The linear region identifies the singularity field and the nonlinear region identifies the region outside the singularity field where (7) is no longer valid [5]. From these plots, the parameters $\lambda, H_{\sigma}$, and $H_{\tau}$ can be calculated by taking the linear region of the graph where the singularity field exits as shown in Figure 5. The values of the strength of the singularity, $\lambda$, compare well with the analytical prediction of 0.3222 given in Figure 6 using (1). The values of singularity parameters are shown in Table 2.

Figures 7 and 8 show that the stress intensity factor of $R L_{0}$ joints $\left(H_{\sigma}=3.3984, H_{\tau}=1.2145\right)$ is greater than singlelap joints with reinforcements and that the stress intensity factor of $R L_{6}$ joints $\left(H_{\sigma}=2.5213, H_{\tau}=0.8905\right)$ is smaller than other single-lap joints with reinforcements. From the singularity analysis, the stress intensity factor of lap joints with reinforcements decreased with increasing reinforcement length. But the influence of reinforcement length on stress intensity factor and joints strength is limited.

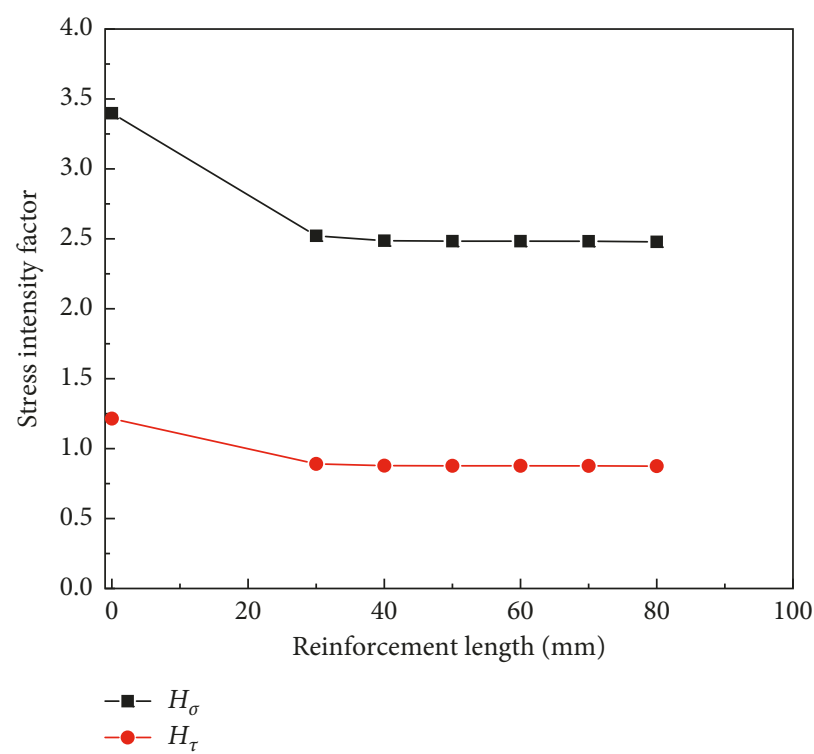

FIgURE 7: Stress intensity factor-reinforcement length.

The stress intensity factor is found to decrease slightly with increasing reinforcement length.

\section{Conclusions}

The reinforcements are often used to improve the strength of adhesive bonding and repair the surface of the damaged structures. This paper has investigated the influence of the reinforcement length on the singular behavior of single-lap joints. The following results were obtained:

(1) The stress intensity factor of single-lap joints was influenced by the reinforcements. The stress intensity factor of single-lap joints can be decreased by the reinforcement. 
TABLE 2: Stress intensity factor in single-lap joints.

\begin{tabular}{lccllr}
\hline Joint types & $\lambda_{1}$ & $\lambda_{2}$ & $\lg \left(H_{\sigma}\right)$ & $\lg \left(H_{\tau}\right)$ & $H_{\sigma}$ \\
\hline$R L_{0}$ joints & 0.32189 & 0.32019 & 0.53127 & 0.08441 & 3.3984 \\
$R L_{1}$ joints & 0.32108 & 0.32121 & 0.40162 & 0.05039 & 2.5213 \\
$R L_{2}$ joints & 0.32108 & 0.32123 & 0.39563 & 0.05641 & 2.4867 \\
$R L_{3}$ joints & 0.32108 & 0.32123 & 0.39506 & 0.05700 & 2.4835 \\
$R L_{4}$ joints & 0.32109 & 0.32123 & 0.39507 & 0.05698 & 2.4835 \\
$R L_{5}$ joints & 0.32109 & 0.32123 & 0.39492 & 0.05712 & 0.87505 \\
$R L_{6}$ joints & 0.32108 & 0.32123 & 0.39414 & 0.05794 & 0.8770 \\
\hline
\end{tabular}

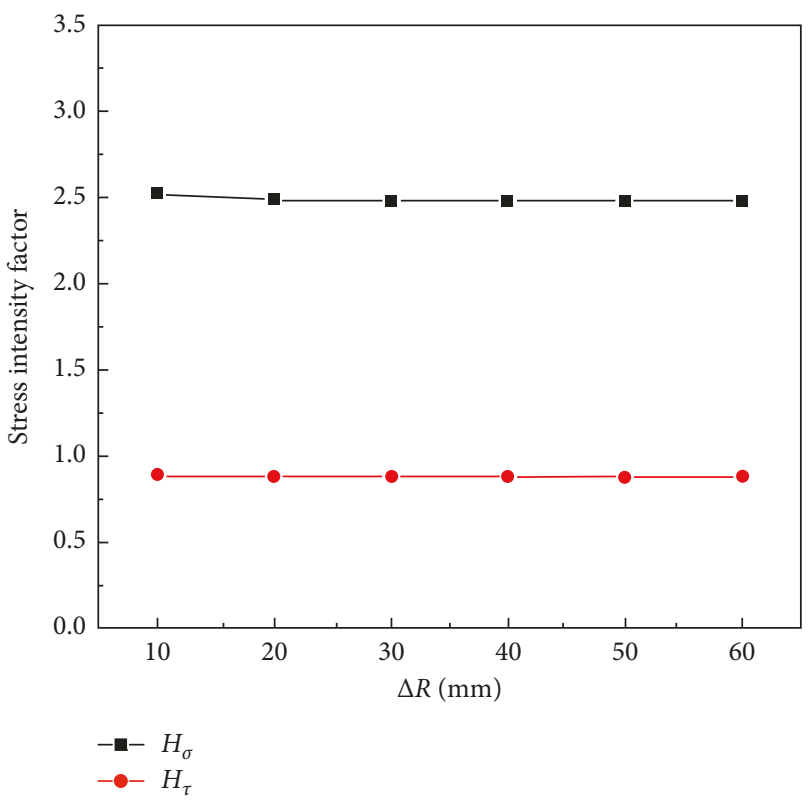

Figure 8: Stress intensity factor- $\Delta(R)$.

(2) The stress intensity factor of single-lap joints with reinforcements was influenced slightly by the reinforcement length. The stress intensity factor of single-lap joints with reinforcements decreased slightly with increasing reinforcement length.

\section{Data Availability}

The data used to support the findings of this study are available from the corresponding author upon request.

\section{Conflicts of Interest}

The authors declare that there are no conflicts of interest regarding the publication of this paper.

\section{Acknowledgments}

This study was supported by the Qingdao Postdoctoral Science Foundation, National Natural Science Foundation of China (nos. 71701109 and 41406106), Natural Science Foundation of Shandong Province (ZR2015EM038), and Taishan Scholar Program of Shandong Province (201511029).

\section{References}

[1] X. He, F. Gu, and A. Ball, "A review of numerical analysis of friction stir welding," Progress in Materials Science, vol. 65, pp. 1-66, 2014.

[2] L. F. M. Da Silva, R. D. Adams, and A. Öchsner, Handbook of Adhesion Technology, Springer, Heidelberg, Germany, 2011.

[3] R. D. Adams, J. Comyn, and W. C. Wake, Structural Adhesive Joints in Engineering, Elsevier Applied Science Publishers, London, UK, 1998.

[4] X. He, "Numerical and experimental investigations of the dynamic response of bonded beams with a single-lap joint," International Journal of Adhesion and Adhesives, vol. 37, pp. 79-85, 2012.

[5] M. J. L. Van Tooren, D. M. Gleich, and A. Beukers, "Experimental verification of a stress singularity model to predict the effect of bondline thickness on joint strength," Journal of Adhesion Science and Technology, vol. 18, no. 4, pp. 395-412, 2004.

[6] R. Breto, A. Chiminelli, M. Lizaranzu, and R. Rafael, "Study of the singular term in mixed adhesive joints," International Journal of Adhesion and Adhesives, vol. 76, pp. 11-16, 2017.

[7] J. H. Tang, I. Sridhar, and N. Srikanth, "Static and fatigue failure analysis of adhesively bonded thick composite single lap joints," Composites Science and Technology, vol. 86, pp. 18-25, 2013.

[8] T. Sawa, J. Liu, K. Nakano, and J. Tanaka, “A two-dimensional stress analysis of single-lap adhesive joints of dissimilar adherends subjected to tensile loads," Journal of Adhesion Science and Technology, vol. 14, no. 1, pp. 43-46, 2000.

[9] L. Goglio and M. Rossetto, "Stress intensity factor in bonded joints: Influence of the geometry," International Journal of Adhesion and Adhesives, vol. 30, no. 5, pp. 313-321, 2010.

[10] Y. Zhang, N. Noda, X. Lan, and K. Takaishi, "Variation of stress intensity factors for several interface crack problems under arbitrary material combinations," Science China Physics, Mechanics and Astronomy, vol. 55, no. 11, pp. 2128-2134, 2012.

[11] N. Noda, T. Miyazaki, R. Li, T. Uchikoba, Y. Sano, and Y. Takase, "Debonding strength evaluation in terms of the intensity of singular stress at the interface corner with and without fictitious crack," International Journal of Adhesion and Adhesives, vol. 61, pp. 46-64, 2015.

[12] D. M. Gleich, M. J. L. Van Tooren, and A. Beukers, "A stress singularity approach to failure initiation in a bonded joint with varying bondline thickness," Journal of Adhesion Science and Technology, vol. 15, no. 10, pp. 1247-1259, 2001.

[13] Q. Zhou, J. Xu, X. Chen, J. Zheng, and C. Zhou, "Stress singularity in a rectangular bond specimen of a solid rocket motor: effects and elimination," International Journal of Adhesion and Adhesives, vol. 63, pp. 57-65, 2015.

[14] B. Kilic, E. Madenci, and D. R. Ambur, "Influence of adhesive spew in bonded single-lap joints," Engineering Fracture Mechanics, vol. 73, no. 11, pp. 1472-1490, 2006. 
[15] M. Imanaka, K. Ishii, and H. Nakayama, "Evaluation of fatigue strength of adhesively bonded single and single step double lap joints based on stress singularity parameters," Engineering Fracture Mechanics, vol. 62, no. 4-5, pp. 409-424, 1999.

[16] Y. Wang, X. He, B. Xing, and C. Deng, "Improvement in strength of adhesively bonded single-lap joints using reinforcements," Journal of Adhesion, vol. 91, no. 6, pp. 434-448, 2015.

[17] D. B. Bogy and K. C. Wang, "Stress singularities at interface corners in bonded dissimilar isotropic elastic materials," International Journal of Solids and Structures, vol. 7, no. 8, pp. 993-1005, 1971.

[18] D. B. Bogy, "Two edge-bonded elastic wedges of different materials and wedge angles under surface tractions," Journal of Applied Mechanics, vol. 38, no. 2, pp. 377-386, 1971. 


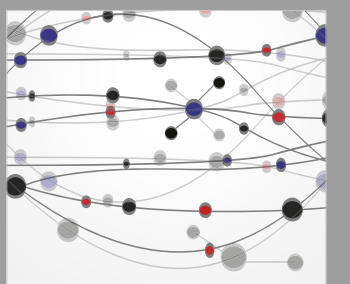

The Scientific World Journal
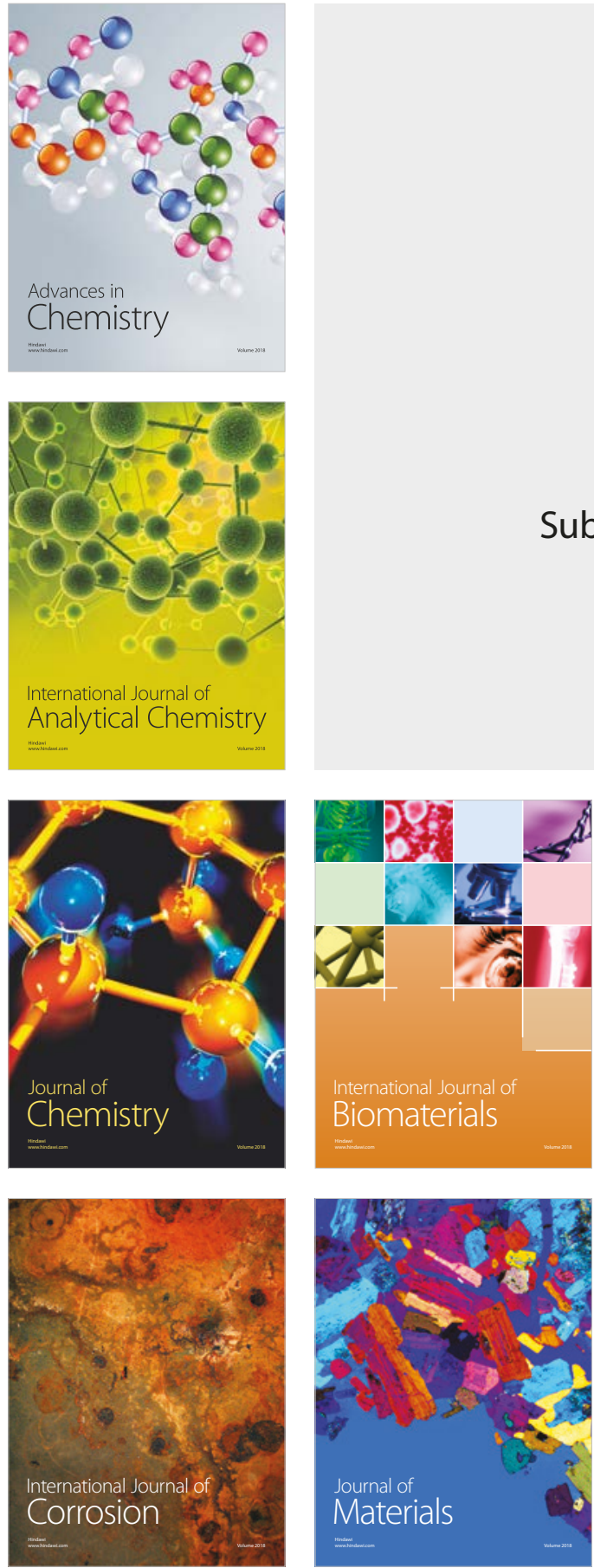

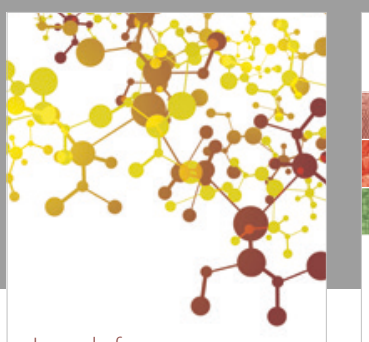

Journal of

Applied Chemistry
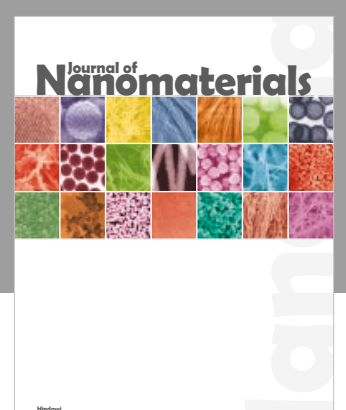

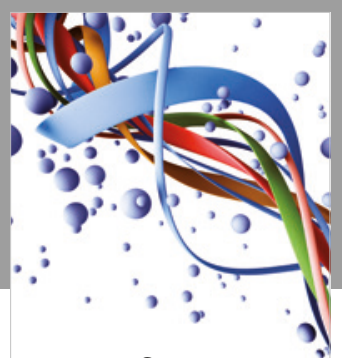

Scientifica

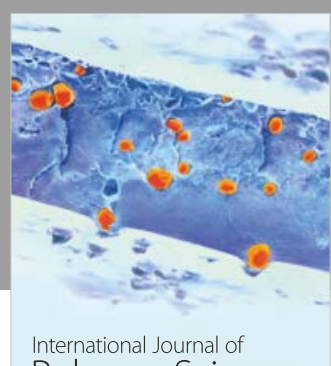

Polymer Science

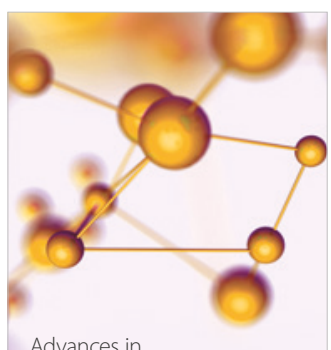

Physical Chemistry
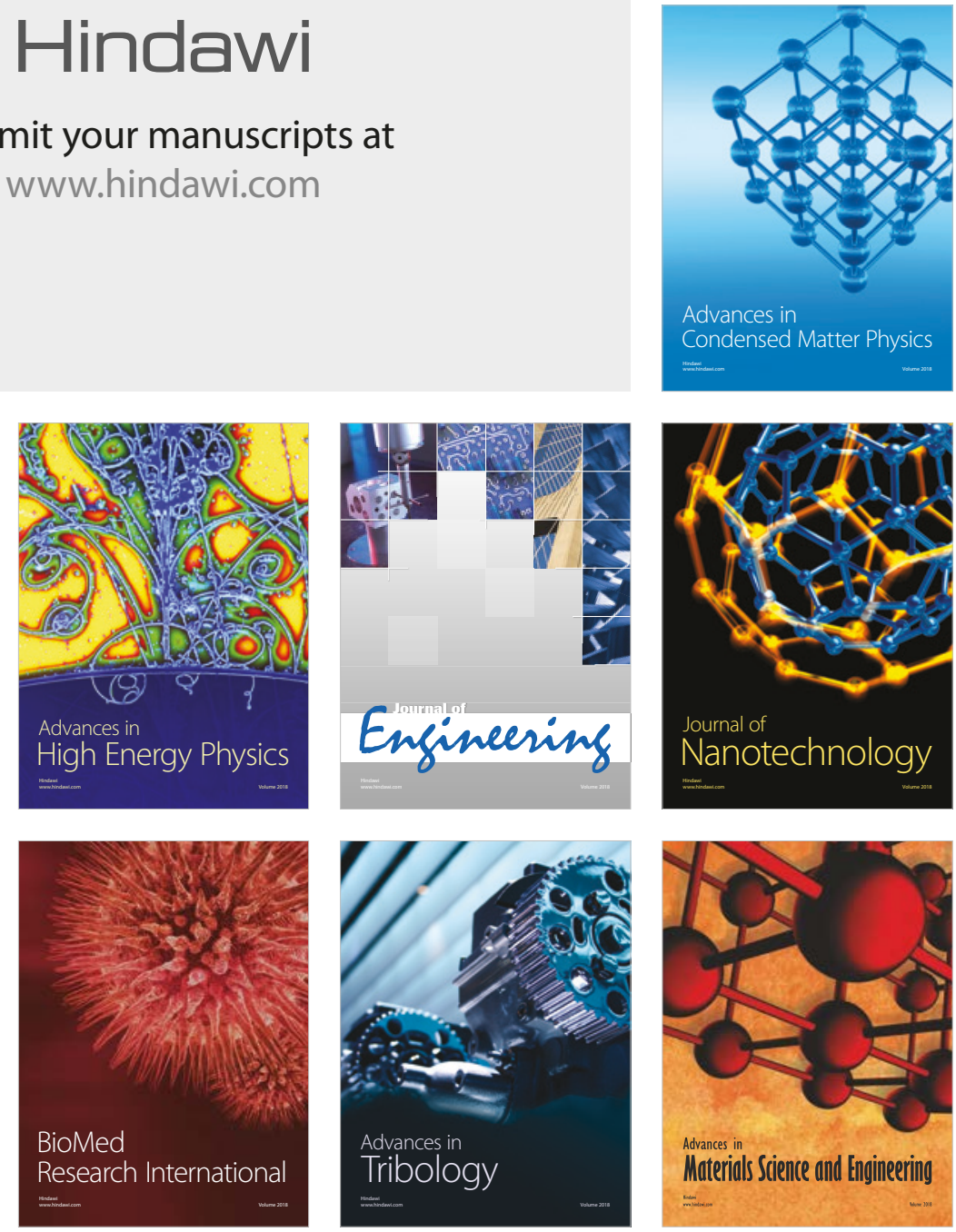